\title{
Risk Factors for Recurrence in Elderly Patients with Stage II Colorectal Cancer: A Multicenter Retrospective Study
}

Takuki Yagyu

Tottori University

Manabu Yamamoto ( $\nabla$ m.yamamoto@tottori-u.ac.jp )

Tottori University

Akimitsu Tanio

Japanese Red Cross Tottori Hospital

Kazushi Hara

Tottori University

Ken Sugezawa

Tottori University

Chihiro Uejima

Tottori University

Kyoichi Kihara

Tottori University

Shigeru Tatebe

Tottori Prefectural Central Hospital

Yasuro Kurisu

National Hospital Organization Hamada Medical Center

Shunsuke Shibata

San-in Rosai Hospital

Toshio Yamamoto

Nojima Hospital

Hiroshi Nishie

Tottori Prefectural Kosei Hospital

Setsujo Shiota

Masuda Red Cross Hospital

Hiroaki Saito

Japanese Red Cross Tottori Hospital

Takuji Naka

National Hospital Organization, Yonago Medical Center

Kenji Sugamura 
Yasugi City Hospital

\section{Kuniyuki Katano}

The Nanbu Town National Health Insurance Saihaku Hospital

\section{Yoshiyuki Fujiwara}

Tottori University

\section{Research Article}

Keywords: GNRI, stagell CRC, elderly patients

Posted Date: February 25th, 2022

DOl: https://doi.org/10.21203/rs.3.rs-1367970/v1

License: (c) (1) This work is licensed under a Creative Commons Attribution 4.0 International License. Read Full License

Version of Record: A version of this preprint was published at BMC Cancer on April 11th, 2022. See the published version at https://doi.org/10.1186/s12885-022-09501-8. 


\section{Abstract}

\section{Background}

Adjuvant chemotherapy for stagell colorectal cancer (CRC)is considered appropriate for patients with risk factorsfor recurrence, rather than for all patients uniformly. However, the risk factors for recurrence remain controversial, and there is limited information, especially for elderly patients. The Geriatric Nutritional Risk Index (GNRI) is widely used as a simple nutritional screening tool in the elderly and is associated with cancer prognosis and recurrence. This study aimed to investigate the risk factors for recurrence in the elderly with stagell CRC, focusing on the GNRI.

\section{Methods}

We enrolled 348elderly patients ( $\geq 75$ years) with stagell CRC who underwent curative resection at the Department of Surgery, Tottori University and our 10 affiliated institutions. The patients were divided into $\mathrm{GNRI}^{\text {high }}(\geq 93.465)$ and GNRI low $(<93.465)$ groups.

\section{Results}

The GNRI ${ }^{\text {low }}$ group showed a significantly worse overall survival (OS), cancer-specific survival (CSS), and relapse-free survival (RFS) $(P<0.001, P<0.001$, and $P<0.001$, respectively).In a multivariate analysis, GNRI $^{\text {low }}$ (hazard ratio [HR]:2.543, $P<0.001$ ), pathologic T4 stage (HR:2.380, $P=0.001$ ), and moderate to severe lymphatic or venous invasion (HR:2.194, $P=0.001$ ) were independent factors affecting RFS. By using these three factors to score the risk of recurrence from 0 to 3 points, the prognosis was significantly stratified in terms of OS, CSS, and RFS ( $P<0.001, P<0.001$, and $P<0.001$, respectively). The recurrence rate for each score was as follows: 0 points, $9.8 \% ; 1$ point, $22.0 \%$; 2 points, $37.3 \%$; and 3 points, $61.9 \%$.

\section{Conclusions}

GNRI $^{\text {low }}$, pathologic T4 stage, and moderate to severe lymphatic or venous invasion are high-risk factors for recurrence in the elderly with stagell CRC. The scoring system using these three factors appropriately predicted their recurrence and outcome.

\section{Background}

The number of elderly patients diagnosed with colorectal cancer (CRC) continues to increase with the aging of the population worldwide. In fact, approximately $40 \%$ of CRC patients are over 75 years [1]. However, because elderly patients are generally excluded from clinical trials, the recommended treatment for this population is more unclear than for non-elderly patients. In particular, elderly patients typically show poor tolerance to chemotherapy, and its administration might worsen their performance status (PS) [2]. In a previous retrospective study, the rate of adjuvant chemotherapy (AC) for patients with stage III CRC decreased dramatically with increasing age: $78 \%$ of patients aged $65-69$ years, $74 \%$ of those aged 
$70-74,58 \%$ of those aged $75-79$ years, $34 \%$ of those aged $80-84$ years, and $11 \%$ of those aged $85-89$ years [3]. However, there is a considerable number of the elderly in a good general condition who may benefit from chemotherapy. An analysis of 5489 patients $\geq 75$ years of age with resected stage III colon cancer reported a survival benefit of 5-fluorouracil-based AC [4].

The clinical efficacy of AC after curative resection in patients with stage II CRC remains controversial. Currently, guidelines recommend that AC for stage II CRC should be targeted to patients at high risk of recurrence rather than uniformly given to all patients [5] [6] [7] [8]. The following variables have been proposed as high-risk factors for recurrence: pathologic T4 stage, perforation, poorly differentiated or undifferentiated adenocarcinoma, venous invasion, lymphatic invasion, and $<12$ dissected lymph nodes [9] [10]. However, few studies have focused on risk factors for the recurrence of stage II CRC in elderly patients. Furthermore, most of these proposed risk factors represent only the progression of the tumor itself. Regarding AC for the elderly, it is advisable to identify high-risk factors specific to elderly patients.

In recent years, it has been reported that not only tumor-specific factors but also patient factors related to nutritional status influence survival outcomes in various cancers [11] [12]. The Geriatric Nutritional Risk Index (GNRI) was first reported as an elderly-specific nutritional assessment index to predict nutritionrelated risks of morbidity and mortality for hospitalized elderly patients [13]. Recent reports have shown that the GNRI is closely associated with the prognosis of various malignant tumors, including CRC [14], gastric cancer [15], and pancreatic cancer [16]. Interestingly, a low GNRI is not only reported to indicate poor overall survival (OS) due to poor nutritional status but also poor cancer-specific survival (CSS) and relapse-free survival (RFS), which might reflect the state of cancer [16] [17] [18].

Therefore, in the present study, we investigated the high-risk factors for recurrence in elderly patients with stage II CRC, focusing on the GNRI.

\section{Methods}

\section{Patients}

The present study included 348 elderly patients aged $\geq 75$ years among a total of 713 patients with pathological stage II CRC who underwent radical surgery at the Department of Surgery, Tottori University and our 10 affiliated institutions from January 2007 to December 2017. The eighth edition of the Union for International Cancer Control Tumor, Node, Metastasis staging system was used to determine the clinicopathological characteristics [19]. The ninth edition of the Japanese Classification of Colorectal, Appendiceal, and Anal Carcinoma by the Japan Society for Cancer of the Colon and Rectum was used to evaluate lymphatic invasion and venous invasion [20]. This study was approved by the Certified Review Board of Tottori University Hospital (18A052) and each institution, and the requirement for informed consent was waived.

\section{Calculation Of The Gnri}


The GNRI is a simple index calculated using serum albumin levels (ALB), ideal body weight (IBW), and actual body weight (ABW), which are easily available. The formula for calculating the GNRI is as follows: $\mathrm{GNRI}=1.487 \times \mathrm{ALB}(\mathrm{g} / \mathrm{L})+41.7 \times \mathrm{ABW} / \mathrm{IBW}(\mathrm{kg})[13] . \mathrm{IBW}$ was calculated as $22 \times$ height $^{2}(\mathrm{~m})$.

\section{Statistical Analyses}

The chi-squared test and Mann-Whitney $\mathrm{U}$ test were used to compare the clinicopathological characteristics. The area under the curve (AUC) was calculated by receiver operating characteristic (ROC) analysis. ROC analysis was also used to determine the Youden index for the GNRI. The Kaplan-Meier method was used to generate survival curves, and their differences were examined using the log-rank test. Multivariate analyses were performed using Cox's proportional hazards model. $P<0.05$ was considered significant. SPSS software (SPSS for Mac Version 25; IBM Corp., Armonk, NY, USA) was used for statistical analyses.

\section{Results}

We first verified the usefulness of the GNRI in predicting recurrence in the elderly. ROC analysis for RFS showed that the GNRI was considered a useful factor in predicting recurrence (AUC $=0.631 ; P<0.001$; Fig. 1). We then divided patients into GNRI ${ }^{\text {high }}(\geq 93.465 ; n=147)$ and $G N R I^{\text {low }}(<93.465 ; n=201)$ groups according to the optimal cutoff values determined by ROC analysis. The relationship between GNRI status and clinicopathological factors is shown in Table 1. In addition to body mass index (BMI) and ALB, which are required to calculate the GNRI, there were significant differences between the two groups in age, Eastern Cooperative Oncology Group (ECOG) PS, C-reactive protein, preoperative carcinoembryonic antigen, obstruction, pathologic $\mathrm{T}$ stage, and lymphatic invasion. 
Table 1

Relationship between GNRI status and clinicopathological factors in elderly patients with stage II colorectal cancer

\begin{tabular}{|c|c|c|c|}
\hline & GNRI $^{\text {high }}(n=147)$ & GNRI $^{\text {low }}(n=201)$ & $P$ value \\
\hline Age & $81(75-95)$ & $83(75-98)$ & $<0.001$ \\
\hline \multicolumn{4}{|l|}{ Sex } \\
\hline Male & $69(46.9 \%)$ & $92(45.8 \%)$ & 0.913 \\
\hline Female & 78 (53.1\%) & 109 (54.2\%) & \\
\hline \multicolumn{4}{|l|}{ ECOG PS } \\
\hline 0,1 & $121(82.3 \%)$ & $113(56.2 \%)$ & $<0.001$ \\
\hline $2,3,4$ & $26(17.7 \%)$ & 88 (43.8\%) & \\
\hline BMI & $23.1(17.8-28.7)$ & $19.5(11.7-28.1)$ & $<0.001$ \\
\hline ALB & $3.9(2.8-4.9)$ & $3.1(1.5-4.8)$ & $<0.001$ \\
\hline CRP & $0.16(0.02-10.30)$ & $0.69(0.02-34.70)$ & $<0.001$ \\
\hline Preoperative CEA & $3.6(0.8-366.0)$ & $4.9(1.0-886.3)$ & 0.015 \\
\hline Preoperative CA19-9 & $11.0(0-8882.2)$ & $9.1(0-5782.0)$ & 0.457 \\
\hline \multicolumn{4}{|l|}{ Location } \\
\hline Colon & $116(78.9 \%)$ & $160(79.6 \%)$ & 0.894 \\
\hline Rectum & $31(21.1 \%)$ & $41(20.4 \%)$ & \\
\hline \multicolumn{4}{|l|}{ Obstruction } \\
\hline Absent & $127(86.4 \%)$ & $135(67.2 \%)$ & $<0.001$ \\
\hline Present & $20(13.6 \%)$ & 66 (32.8\%) & \\
\hline \multicolumn{4}{|l|}{ Perforation } \\
\hline Absent & $143(97.3 \%)$ & $192(95.5 \%)$ & 0.569 \\
\hline Present & $4(2.7 \%)$ & $9(4.5 \%)$ & \\
\hline \multicolumn{4}{|l|}{ Histology ${ }^{a}$} \\
\hline tub & $135(91.8 \%)$ & $176(87.6 \%)$ & 0.222 \\
\hline por, muc & $12(8.2 \%)$ & $25(12.4 \%)$ & \\
\hline \multicolumn{4}{|l|}{ Pathologic T stage ${ }^{b}$} \\
\hline $\mathrm{T} 1, \mathrm{~T} 2, \mathrm{~T} 3$ & $133(90.5 \%)$ & $152(75.6 \%)$ & $<0.001$ \\
\hline
\end{tabular}




\begin{tabular}{|c|c|c|c|}
\hline & GNRI ${ }^{\text {high }}(n=147)$ & GNRI'low $(n=201)$ & $P$ value \\
\hline T4 & $14(9.5 \%)$ & $49(24.4 \%)$ & \\
\hline \multicolumn{4}{|c|}{ Lymphatic invasion ${ }^{c}$} \\
\hline Ly0, 1a & 129 (87.8\%) & $154(76.6 \%)$ & 0.008 \\
\hline Ly1b, c & $18(12.2 \%)$ & $47(23.4 \%)$ & \\
\hline \multicolumn{4}{|c|}{ Vascular invasion ${ }^{d}$} \\
\hline V0, 1a & $110(74.8 \%)$ & $154(76.6 \%)$ & 0.706 \\
\hline V1b, c & $37(25.2 \%)$ & $47(23.4 \%)$ & \\
\hline \multicolumn{4}{|c|}{ Adjuvant chemotherapy } \\
\hline Absent & $128(87.1 \%)$ & 179 (89.1\%) & 0.615 \\
\hline Present & $19(12.9 \%)$ & $22(10.9 \%)$ & \\
\hline \multicolumn{4}{|c|}{$\begin{array}{l}\text { GNRI: Geriatric Nutritional Risk Index; ECOG PS: Eastern Cooperative Oncology Group Performance } \\
\text { Status; BMI: body mass index; ALB: serum albumin level; CRP: C-reactive protein; CEA: } \\
\text { carcinoembryonic antigen; CA19-9: carbohydrate antigen } 19-9 \text {. }\end{array}$} \\
\hline \multicolumn{4}{|c|}{$\begin{array}{l}\text { a Histology: tub, tubular adenocarcinoma; por, poorly differentiated adenocarcinoma; muc, mucinous } \\
\text { adenocarcinoma. }\end{array}$} \\
\hline \multicolumn{4}{|c|}{$\begin{array}{l}\text { b Pathologic T stage: T1, Tumor is confined to the submucosa and does not invade the muscularis } \\
\text { propria (MP); T2, Tumor invasion to, but not beyond, the MP; T3, Tumor invades beyond the MP. In } \\
\text { sites with serosa, the tumor grows into the subserosa. In sites with no serosa, the tumor grows into } \\
\text { the adventitia; T4, Tumor invades or perforates the serosa or directly invades other organs or } \\
\text { structures. }\end{array}$} \\
\hline \multicolumn{4}{|c|}{$\begin{array}{l}\text { ' Lymphatic invasion: L1a, Minimal lymphatic invasion; L1b, Moderate lymphatic invasion; L1c, } \\
\text { Severe lymphatic invasion. }\end{array}$} \\
\hline \multicolumn{4}{|c|}{$\begin{array}{l}\text { d Vascular invasion: V1a, Minimal venous invasion; V1b, Moderate venous invasion; V1c, Severe } \\
\text { venous invasion. }\end{array}$} \\
\hline
\end{tabular}

The prognosis of the GNRI ${ }^{\text {low }}$ group was worse than that of the GNR ${ }^{\text {high }}$ group in terms of 5 -year OS ( $54.6 \%$ vs. $78.6 \%$, respectively; $P<0.001$; Fig. 2 a), 5 -year CSS (78.3\% vs. $93.2 \%$, respectively; $P<0.001$; Fig. 2b), and 5-year RFS (40.8\% vs. $70.9 \%$, respectively; $P<0.001$; Fig. 2 c).

In a multivariate analysis, GNRI low (hazard ratio [HR]: $2.543,95 \%$ confidence interval [Cl]: $1.552-4.250, P$ $<0.001$ ), pathologic T4 stage (HR: $2.380,95 \% \mathrm{Cl}: 1.442-3.928, P=0.001$ ), and moderate to severe lymphatic or venous invasion (HR: $2.194,95 \% \mathrm{Cl}: 1.402-3.435, P=0.001)$ were independent and significant factors affecting RFS (Table 2). 
Table 2

Multivariate analyses for recurrence-free survival in elderly patients with stage II colorectal cancer

\begin{tabular}{|c|c|c|c|c|}
\hline & & \multicolumn{2}{|r|}{$\begin{array}{l}\text { Relapse free } \\
\text { survival }\end{array}$} & \multirow[b]{2}{*}{$P$ value } \\
\hline & & $\mathrm{HR}$ & $95 \% \mathrm{Cl}$ & \\
\hline Obstruction & Present vs. absent & 0.792 & $0.476-1.319$ & 0.37 \\
\hline Perforation & Present vs. absent & 2.328 & $0.917-5.908$ & 0.075 \\
\hline Pathologic T stage & T4 vs. others & 2.38 & $1.442-3.928$ & 0.001 \\
\hline $\begin{array}{l}\text { Lymphatic/venous } \\
\text { invasion }\end{array}$ & Ly or V1b/c vs. others & 2.194 & $1.402-3.435$ & 0.001 \\
\hline Histology & muc or por vs. others & 0.833 & $0.414-1.676$ & 0.609 \\
\hline CEA & $\begin{array}{l}\geq 5.0 \mathrm{ng} / \mathrm{ml} \text { vs. }<5.0 \\
\mathrm{ng} / \mathrm{ml}\end{array}$ & 1.236 & $0.800-1.910$ & 0.34 \\
\hline GNRI & $<93.465$ vs. $\geq 93.465$ & 2.543 & $1.522-4.250$ & $<0.001$ \\
\hline Adjuvant chemotherapy & Present vs. absent & 0.731 & $0.392-1.363$ & 0.324 \\
\hline \multicolumn{5}{|c|}{$\begin{array}{l}\text { Cl: confidence interval; HR: hazard ratio; CEA: carcinoembryonic antigen; GNRI: Geriatric Nutritional } \\
\text { Risk Index. }\end{array}$} \\
\hline
\end{tabular}

Previous reports have shown a relationship between the number of risk factors for recurrence and survival in patients with stage II CRC and suggested that AC is more beneficial for patients with multiple risk factors [21] [22] [23]. We considered that the adverse effects of AC should be carefully evaluated for elderly patients and that more accurate identification of high-risk patients was warranted. Therefore, we finally developed a scoring system (from 0 to 3 points) to predict recurrence using three independent factors obtained by multivariate analysis. As shown in Fig. 3, the proposed scoring system predicted the patient's outcome in terms of OS (5-year OS rates, $78.6 \%$ vs. $65.3 \%$ vs. $53.7 \%$ vs. $34.5 \%$, respectively; $P<$ 0.001 ; Fig. 3a), CSS (5-year CSS rates, $94.3 \%$ vs. $88.0 \%$ vs. $75.6 \%$ vs. $44.7 \%$, respectively; $P<0.001$; Fig. 3b), and RFS (5-year RFS rates, $75.1 \%$ vs. $53.1 \%$ vs. $35.6 \%$ vs. $24.8 \%$, respectively; $P<0.001$; Fig. 3 c). Regarding RFS, the survival curves for each score were generally evenly spaced. Furthermore, the recurrence rate for each score was as follows: 0 points, $9.8 \%$; 1 point, $22.0 \%$; 2 points, $37.3 \%$; and 3 points, $61.9 \%$.

\section{Discussion}

Our study showed that low GNRI level is a prognostic and high-risk factor for recurrence in elderly patients with stage II CRC and that the scoring system using the GNRI, pathologic T4 stage, and lymphatic/venous invasion could stratify patient outcomes in terms of OS, CSS, and RFS. 
In recent years, not only the severity of tumor progression but also the patient's poor nutritional condition have been considered to affect prognosis and recurrence. Several nutritional assessment tools, including the prognostic nutritional index [24], controlling nutritional status [25], and Glasgow prognostic score [26], have been reported as prognostic factors for patients with various cancers. Although these tools are inexpensive and objective, their clinical application is limited because of a lack of consensus in the elderly. In contrast, the GNRI was originally designed to assess nutritional risk for hospitalized elderly patients [13]. Furthermore, this index is calculated using ALB, height, and body weight, which are usually measured before surgery.

Hypoalbuminemia is a known indicator of malnutrition and is closely associated with systemic inflammation and poor immune responses. Tumor-induced systemic inflammation promotes tumorigenesis, invasion, and metastasis via inflammatory mediators, such as tumor necrosis factoralpha, interleukin-6, and interleukin-10 [27] [28]. Additionally, nutritional deficiencies impair cell-mediated immunity and the function of cytokines and phagocytes, leading to an inadequate anti-tumor immune reaction [29]. Indeed, hypoalbuminemia has been reported as a prognostic factor for immune-checkpoint therapy (ICT) in lung cancer [30], and the Gustave Roussy Immune Score, which is used as a prognostic indicator for ICT, includes low albumin as one of its components [31]. In addition, lower ABW/IBW, which indicates lower BMI, reflects frailty and cachexia and is associated with poor prognosis in elderly patients with cancer [32]. Furthermore, BMI may also be related to tumor immunity. It has been reported that adipose tissue activates cytotoxic T-cells and reduces regulatory T-cells; therefore, a higher BMI leads to a greater effect of ICT [33] [34]. These findings support our results that a low GNRI reflects recurrence and poor prognosis in CRC.

Although nutritional status along with tumor-specific factors is considered important to evaluate patient outcomes, the risk factors for recurrence of stage II CRC reported to date are only related to tumor progression, and to the best of our knowledge, no reports have described nutritional assessment factors. In this study, pathologic T4 stage and lymphatic/venous invasion, which indicate advanced tumor progression, and a low GNRI, which indicates malnutrition, were identified as independent predictors of recurrence, suggesting that both tumor and patient's nutritional factors have a significant impact on the outcome of elderly patients with stage II CRC.

In this study, our scoring system showed that the recurrence rate increased progressively as the score increased. Patients with 2 points had a $37.3 \%$ recurrence rate, which is almost equal to or higher than the recurrence rate of stage III CRC patients [35]. A recent study reported that AC improved RFS and OS in stage II CRC patients over 70 years of age with a greater number of risk factors for recurrence, whereas patients with fewer risk factors benefited less [23]. In addition, another study reported that AC for patients with stage II CRC over the age of 70 years did not improve RFS, CSS, or OS as well as in the overall cohort [36]. In contrast, AC prolonged OS for stage III CRC patients older than 75 years [4]. Taken together, AC for elderly patients with stage II CRC may be effective in a limited number of patients whose risk of recurrence is equivalent to that of stage $\mathrm{III}$, and $\geq 2$ points in this scoring system might be the cutoff for 
identifying patients who will benefit from AC. This hypothesis should be investigated in future prospective research.

There are several limitations to this study. First, it is a retrospective cohort study, and the number of cases is not large. Second, surgical techniques, such as the omission of extensive lymph node dissection in the elderly, are not standardized among institutions, which may introduce bias and affect the generalizability of the findings. Third, low GNRI values reflect malnutrition and poor general health; therefore, these patients may not necessarily tolerate chemotherapy. In fact, in our study, a low GNRI was strongly correlated with poor ECOG PS. Fourth, we performed this study with the definition of elderly patients as 75 years and older. Life expectancy has been increasing, and similar studies targeting patients over 80 years of age may be needed.

\section{Conclusions}

GNRI $^{\text {low }}$ (<93.465), pathologic T4 stage, and moderate to severe lymphatic or venous invasion are highrisk factors for recurrence in elderly patients with stage II CRC. The scoring system using these three factors appropriately predicted recurrence rates and outcomes, which may contribute to the decision of appropriate cases for AC.

\section{Abbreviations}

CRC, colorectal cancer; PS, performance status; AC, adjuvant chemotherapy; GNRI, Geriatric Nutritional Risk Index; OS, overall survival; CSS, cancer-specific survival; RFS, relapse-free survival; ALB, albumin; IBW, ideal body weight; ABW, actual body weight; AUC, area under the curve; ROC, receiver operating characteristic; BMI, body mass index; ECOG, Eastern Cooperative Oncology Group; HR, hazard ratio; $\mathrm{Cl}$, confidence interval; ICT, immune-checkpoint therapy

\section{Declarations}

\section{Ethics approval and consent to participate}

All procedures performed in this study involving human participants were in accordance with the ethical standards of the institutional review board of ethics committee and national research committee with the 1964 Helsinki declaration and its later amendments. The Tottori University Hospital Ethics Committee approved this study (No. 18A052), and the need for informed consent was waived by the Tottori University Ethics Committee.

\section{Consent for publication}

Not applicable.

\section{Availability of data and materials}


The datasets used and analyzed during the current study are not publicly available due to their containing information that could compromise the privacy of research participants but are available from the corresponding author on reasonable request.

\section{Competing interests}

The authors declare that they have no competing interests.

\section{Funding}

There was no funding source.

Authors' contributions

TY and MY participated in the design of the study, interpretation of data, analysis, and drafting the article. MY, AT, KH, KS, CU, KK, ST, YK, SS, TY, HN, SS, HS, TN, KS, and KK collecteddata. YF revised the article. All authors read and approved the final version ofthe article.

\section{Acknowledgments}

We thank Melissa Crawford, PhD, from Edanz (https://jp.edanz.com/ac) for editing a draft of this manuscript.

\section{References}

1. van Steenbergen LN, Elferink MAG, Krijnen P, Lemmens V, Siesling S, Rutten HJT, Richel DJ, KarimKos HE, Coebergh JWW: Improved survival of colon cancer due to improved treatment and detection: a nationwide population-based study in The Netherlands 1989-2006. Ann Onco/ 2010, 21(11):22062212.

2. Jensen SA, Vilmar A, Sørensen JB: Adjuvant chemotherapy in elderly patients (>or=75 yr) completely resected for colon cancer stage III compared to younger patients: toxicity and prognosis. Med Oncol 2006, 23(4):521-531.

3. Schrag D, Cramer LD, Bach PB, Begg CB: Age and adjuvant chemotherapy use after surgery for stage III colon cancer. J Natl Cancer Inst 2001, 93(11):850-857.

4. Sanoff HK, Carpenter WR, Stürmer T, Goldberg RM, Martin CF, Fine JP, McCleary NJ, Meyerhardt JA, Niland J, Kahn KL et al: Effect of adjuvant chemotherapy on survival of patients with stage III colon cancer diagnosed after age 75 years. J Clin Oncol 2012, 30(21):2624-2634.

5. Figueredo A, Charette ML, Maroun J, Brouwers MC, Zuraw L: Adjuvant therapy for stage II colon cancer: a systematic review from the Cancer Care Ontario Program in evidence-based care's gastrointestinal cancer disease site group. J Clin Oncol 2004, 22(16):3395-3407.

6. Matsuda C, Ishiguro M, Teramukai S, Kajiwara Y, Fujii S, Kinugasa Y, Nakamoto Y, Kotake M, Sakamoto $\mathrm{Y}$, Kurachi $\mathrm{K}$ et al: A randomised-controlled trial of 1-year adjuvant chemotherapy with oral 
tegafur-uracil versus surgery alone in stage II colon cancer: SACURA trial. Eur J Cancer 2018, 96:5463.

7. Hashiguchi Y, Muro K, Saito Y, Ito Y, Ajioka Y, Hamaguchi T, Hasegawa K, Hotta K, Ishida H, Ishiguro M et al: Japanese Society for Cancer of the Colon and Rectum (JSCCR) guidelines 2019 for the treatment of colorectal cancer. Int J Clin Oncol 2020, 25(1):1-42.

8. Baxter NN, Kennedy EB, Bergsland E, Berlin J, George TJ, Gill S, Gold PJ, Hantel A, Jones L, Lieu C et al: Adjuvant Therapy for Stage II Colon Cancer: ASCO Guideline Update. J Clin Oncol 2021:Jco2102538.

9. Benson AB, 3rd, Schrag D, Somerfield MR, Cohen AM, Figueredo AT, Flynn PJ, Krzyzanowska MK, Maroun J, McAllister P, Van Cutsem E et al: American Society of Clinical Oncology recommendations on adjuvant chemotherapy for stage II colon cancer. J Clin Oncol 2004, 22(16):3408-3419.

10. Schmoll HJ, Van Cutsem E, Stein A, Valentini V, Glimelius B, Haustermans K, Nordlinger B, van de Velde CJ, Balmana J, Regula $\mathrm{J}$ et al: ESMO Consensus Guidelines for management of patients with colon and rectal cancer. a personalized approach to clinical decision making. Ann Oncol2012, 23(10):2479-2516.

11. Yamamoto T, Kawada K, Obama K: Inflammation-Related Biomarkers for the Prediction of Prognosis in Colorectal Cancer Patients. Int J Mol Sci 2021, 22(15).

12. Jiang $Y, X u B$, Song $H$, Qiu B, Tian D, Li Z, Ji Y, Wang J: Inflammation and nutrition-based biomarkers in the prognosis of oesophageal cancer: a systematic review and meta-analysis. BMJ Open 2021, 11(9): 048324.

13. Bouillanne O, Morineau G, Dupont C, Coulombel I, Vincent JP, Nicolis I, Benazeth S, Cynober L, Aussel C: Geriatric Nutritional Risk Index: a new index for evaluating at-risk elderly medical patients. $A m \mathrm{~J}$ Clin Nutr 2005, 82(4):777-783.

14. Sasaki M, Miyoshi N, Fujino S, Ogino T, Takahashi H, Uemura M, Matsuda C, Yamamoto H, Mizushima T, Mori $\mathrm{M}$ et al: The Geriatric Nutritional Risk Index predicts postoperative complications and prognosis in elderly patients with colorectal cancer after curative surgery. Sci Rep 2020, 10(1):10744.

15. Hirahara N, Matsubara T, Fujii Y, Kaji S, Hyakudomi R, Yamamoto T, Uchida Y, Miyazaki Y, Ishitobi K, Kawabata $Y$ et al: Preoperative geriatric nutritional risk index is a useful prognostic indicator in elderly patients with gastric cancer. Oncotarget 2020, 11(24):2345-2356.

16. Sakamoto T, Yagyu T, Uchinaka E, Miyatani K, Hanaki T, Kihara K, Matsunaga T, Yamamoto M, Tokuyasu N, Honjo $S$ et al: The prognostic significance of combined geriatric nutritional risk index and psoas muscle volume in older patients with pancreatic cancer. BMC Cancer 2021, 21(1):342.

17. Shoji F, Matsubara T, Kozuma Y, Haratake N, Akamine T, Takamori S, Katsura M, Toyokawa G, Okamoto T, Maehara Y: Preoperative Geriatric Nutritional Risk Index: A predictive and prognostic factor in patients with pathological stage I non-small cell lung cancer. Surg Oncol 2017, 26(4):483488. 
18. Kanno H, Goto Y, Sasaki S, Fukutomi S, Hisaka T, Fujita F, Akagi Y, Okuda K: Geriatric nutritional risk index predicts prognosis in hepatocellular carcinoma after hepatectomy: a propensity score matching analysis. Sci Rep 2021, 11(1):9038.

19. Brierley JD, Gospodarowicz MK, Wittekind C: TNM classification of malignant tumours: John Wiley \& Sons; 2017.

20. Japanese Classification of Colorectal, Appendiceal, and Anal Carcinoma: the 3d English Edition [Secondary Publication]. J Anus Rectum Colon 2019, 3(4):175-195.

21. Babcock BD, Aljehani MA, Jabo B, Choi AH, Morgan JW, Selleck MJ, Luca F, Raskin E, Reeves ME, Garberoglio CA et al: High-Risk Stage II Colon Cancer: Not All Risks Are Created Equal. Ann Surg Oncol 2018, 25(7):1980-1985.

22. Kim MK, Won DD, Park SM, Kim T, Kim SR, Oh ST, Sohn SK, Kang MY, Lee IK: Effect of Adjuvant Chemotherapy on Stage II Colon Cancer: Analysis of Korean National Data. Cancer Res Treat 2018, 50(4):1149-1163.

23. Lee Y, Park I, Cho H, Gwak G, Yang K, Bae BN: Effect of Adjuvant Chemotherapy on Elderly Stage II High-Risk Colorectal Cancer Patients. Ann Coloproctol 2021, 37(5):298-305.

24. Tominaga T, Nagasaki T, Akiyoshi T, Fukunaga Y, Honma S, Nagaoka T, Matsui S, Minami H, Miyanari $\mathrm{S}$, Yamaguchi $\mathrm{T}$ et al: Prognostic nutritional index and postoperative outcomes in patients with colon cancer after laparoscopic surgery. Surg Today 2020, 50(12):1633-1643.

25. Kuroda D, Sawayama H, Kurashige J, Iwatsuki M, Eto T, Tokunaga R, Kitano Y, Yamamura K, Ouchi M, Nakamura $\mathrm{K}$ et al: Controlling Nutritional Status (CONUT) score is a prognostic marker for gastric cancer patients after curative resection. Gastric Cancer 2018, 21(2):204-212.

26. Li MX, Bi XY, Li ZY, Huang Z, Han Y, Zhou JG, Zhao JJ, Zhang YF, Zhao H, Cai JQ: Prognostic Role of Glasgow Prognostic Score in Patients With Hepatocellular Carcinoma: A Systematic Review and Meta-Analysis. Medicine (Baltimore) 2015, 94(49):e2133.

27. Landskron G, De la Fuente M, Thuwajit $P$, Thuwajit $C$, Hermoso MA: Chronic inflammation and cytokines in the tumor microenvironment. $J$ Immunol Res 2014, 2014:149185.

28. Diakos Cl, Charles KA, McMillan DC, Clarke SJ: Cancer-related inflammation and treatment effectiveness. Lancet Oncol 2014, 15(11):e493-503.

29. Saunders J, Smith T, Stroud M: Malnutrition and undernutrition. Medicine 2011, 39(1):45-50.

30. Guo Y, Wei L, Patel SH, Lopez G, Grogan M, Li M, Haddad T, Johns A, Ganesan LP, Yang Y: Serum Albumin: Early Prognostic Marker of Benefit for Immune Checkpoint Inhibitor Monotherapy But Not Chemoimmunotherapy. Clinical Lung Cancer 2022.

31. Bigot F, Castanon E, Baldini C, Hollebecque A, Carmona A, Postel-Vinay S, Angevin E, Armand J-P, Ribrag V, Aspeslagh S: Prospective validation of a prognostic score for patients in immunotherapy phase I trials: The Gustave Roussy Immune Score (GRIm-Score). European Journal of Cancer 2017, 84:212-218.

32. Fried LP, Tangen CM, Walston J, Newman AB, Hirsch C, Gottdiener J, Seeman T, Tracy R, Kop WJ, Burke G et al: Frailty in older adults: evidence for a phenotype. J Gerontol A Biol Sci Med Sci 2001, 
56(3):M146-156.

33. Cortellini A, Bersanelli M, Buti S, Cannita K, Santini D, Perrone F, Giusti R, Tiseo M, Michiara M, Di Marino $\mathrm{P}$ et al: A multicenter study of body mass index in cancer patients treated with anti-PD-1/PDL1 immune checkpoint inhibitors: when overweight becomes favorable. J Immunother Cancer 2019, 7(1):57.

34. Ichihara E, Harada D, Inoue K, Sato K, Hosokawa S, Kishino D, Watanabe K, Ochi N, Oda N, Hara N et al: The impact of body mass index on the efficacy of anti-PD-1/PD-L1 antibodies in patients with non-small cell lung cancer. Lung Cancer 2020, 139:140-145.

35. Osterman E, Glimelius B: Recurrence Risk After Up-to-Date Colon Cancer Staging, Surgery, and Pathology: Analysis of the Entire Swedish Population. Dis Colon Rectum 2018, 61(9):1016-1025.

36. Lee KY, Park JW, Lee KY, Cho S, Kwon YH, Kim MJ, Ryoo SB, Jeong SY, Park KJ: Adjuvant chemotherapy does not provide survival benefits to elderly patients with stage II colon cancer. Sci Rep 2019, 9(1):11846.

\section{Figures}

\section{Yagyu et al. Figure 1}

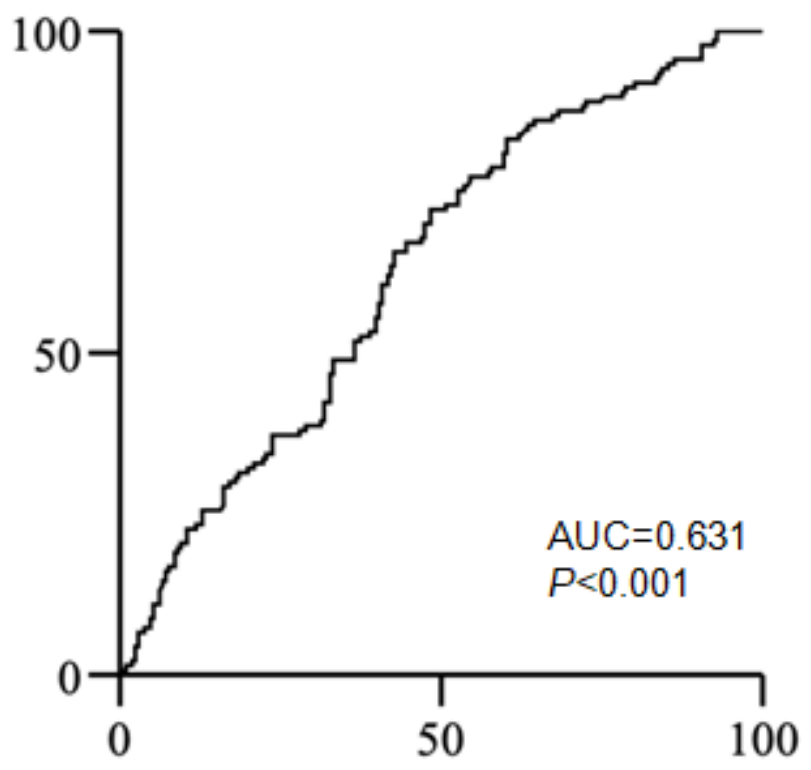

Figure 1

Receiver operating characteristic curves of GNRI for relapse-free survival.

GNRI, geriatric nutritional risk index; AUC, area under the curve 


\section{Yagyu et al. Figure 2}

(a)

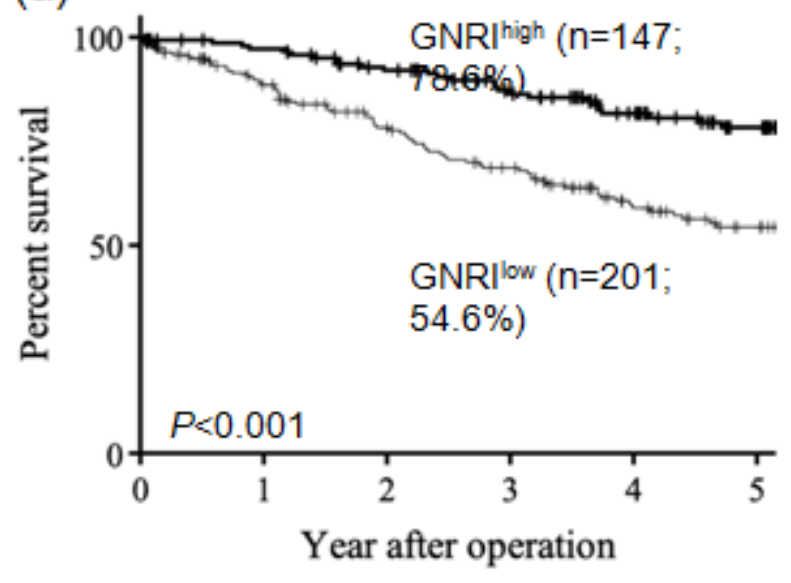

(b)

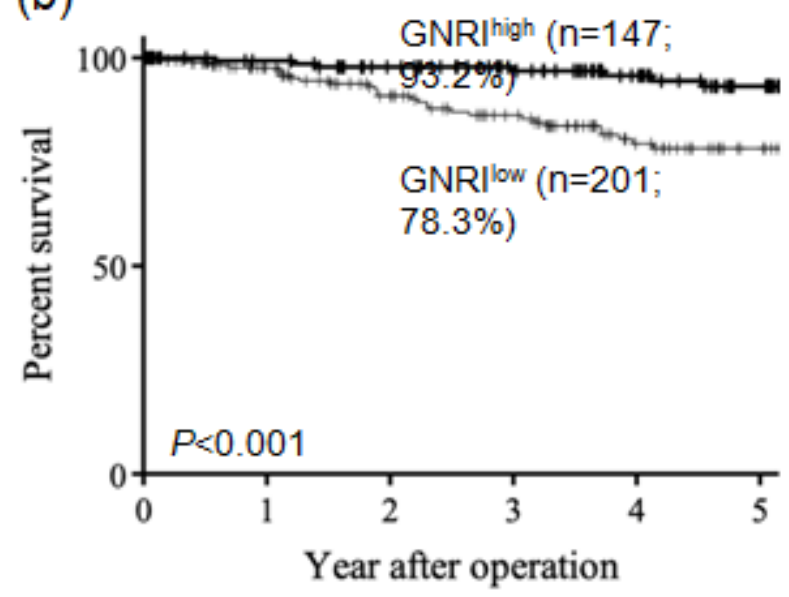

(c)

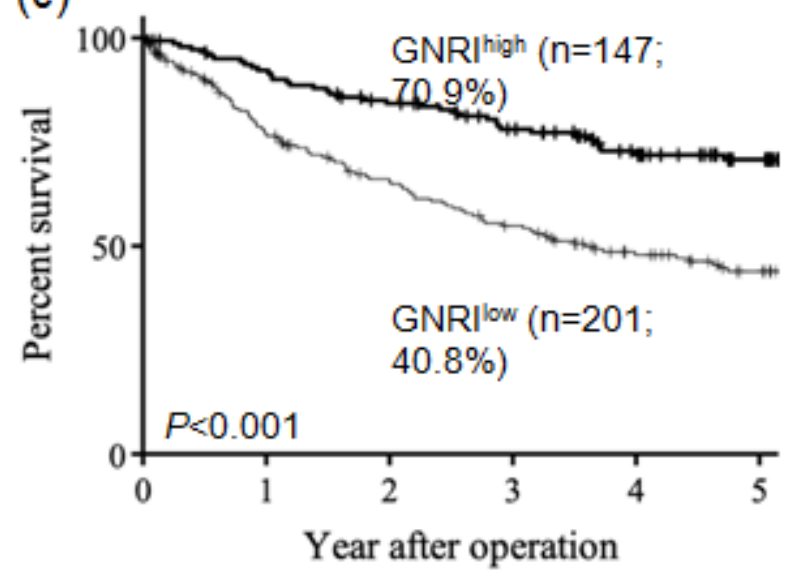

\section{Figure 2}

Kaplan-Meier curves according to the GNRI for overall (a), cancer-specific (b), and relapse-free (c) survival.

GNRI, geriatric nutritional risk index 


\section{Yagyu et al. Figure 3}

(a)

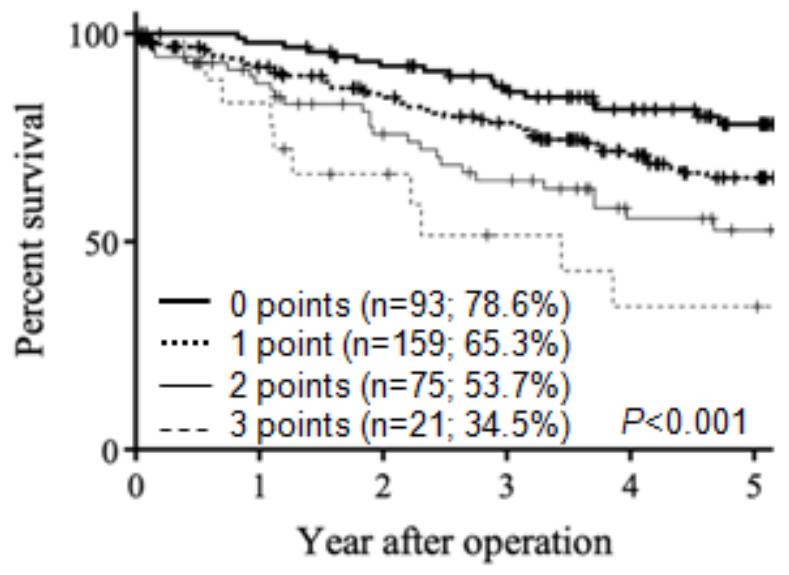

(b)

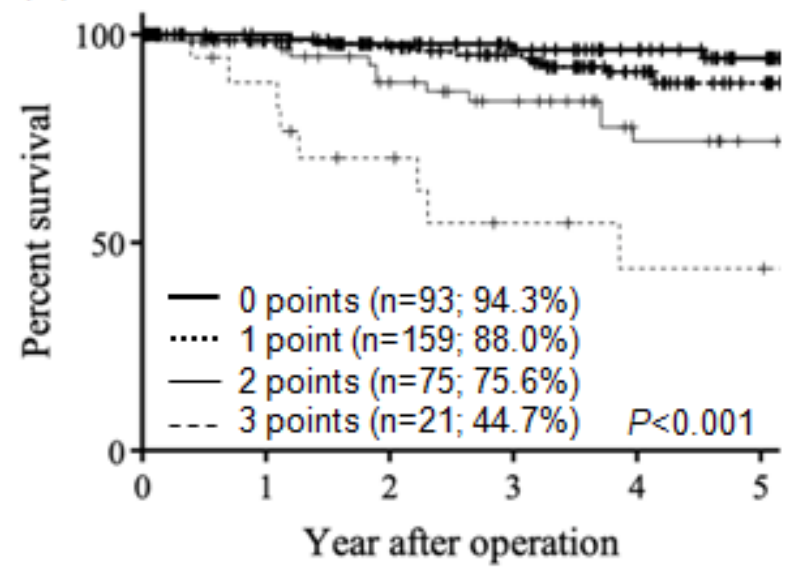

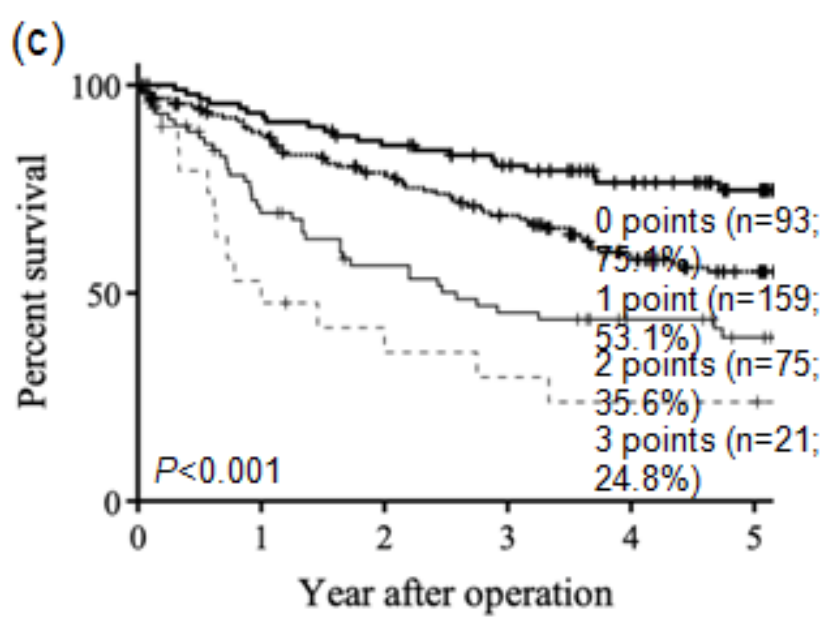

Figure 3

Kaplan-Meier curves according to recurrence prediction scores for overall (a), cancer-specific (b), and relapse-free (c) survival. 